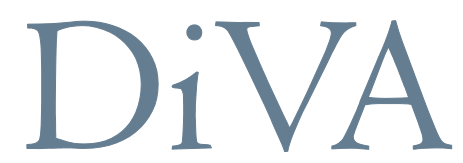

http://uu.diva-portal.org

This is an author produced version of a paper published in IEEE Journal of Oceanic Engineering. This paper has been peer-reviewed but does not include the final publisher proof-corrections or journal pagination.

Citation for the published paper:

Tyrberg S., Waters R., Leijon M.

"Wave Power Absorption as a Function of Water Level and Wave Height: Theory and Experiment"

IEEE Journal of Oceanic Engineering, 2010, Vol. 35(3), pp. 558-564

URL: http://dx.doi.org/10.1109/JOE.2010.2052692

Access to the published version may require subscription.

(C) 2010 IEEE. Personal use of this material is permitted. Permission from IEEE must be obtained for all other users, including reprinting/ republishing this material for advertising or promotional purposes, creating new collective works for resale or redistribution to servers or lists, or reuse of any copyrighted components of this work in other works. 


\title{
Wave power absorption as a function of water level and wave height: theory and experiment
}

\author{
Simon Tyrberg, Rafael Waters, Student Member, IEEE, and Mats Leijon, Member, IEEE
}

\begin{abstract}
This paper investigates the sensitivity of a wave power system to variations in still water levels and significant wave heights. The system consists of a floating point absorber connected to a linear generator on the seabed. Changing still water levels are expected to affect the power absorption, since they will displace the equilibrium position for the generator translator. Similarly, changing significant wave heights will affect the rate at which the translator leaves the stator. Both these effects will in some cases result in a smaller active area of the stator. A theoretical expression to describe this effect is derived, and compared to measured experimental values for the wave energy converter $L 1$ at the Lysekil research site. During the time of measurements, the still water levels at the site were in the range of $[-0.70 \mathrm{~m},+0.46 \mathrm{~m}]$, and the significant wave heights in the range of $[0 \mathrm{~m}, 2.7 \mathrm{~m}]$. The experimental values exhibit similar characteristics as the theoretical expression, especially with changing significant wave heights.
\end{abstract}

\section{INTRODUCTION}

A number of projects around the world are currently investigating the possibilities to extract electrical energy from ocean waves, see for example [1]-[6]. Comparing the strategies of these projects, there are very differing technical solutions put forth. Each technology brings a unique set of questions to be answered. The concept described in this paper consists of a buoy at the surface, connected to a direct drive linear permanent magnet generator on the seabed. An illustration of the technology can be seen in Fig. 1.

In 2006 the first wave energy converter in this project, L1, was deployed at the Lysekil research site on the Swedish west coast. It was initially test run for three months. This paper will investigate how the power absorption of L1 varies with the changing water levels and wave heights at the site. Earlier papers have described the project in general, and have presented other results from the test run, see e. g. [7]-[9].

Since the buoy position will affect the translator position, and the since the stator area will not be $100 \%$ active for all translator positions, changing still water levels and wave heights are expected to have some impact on the performance of the generator. The scope of this impact is dependent on many factors, such as the respective lengths of the translator and the stator, and the stroke length of the translator. The lengths of the translator and stator determine the fraction of active area for a given translator position and the stroke length of the translator sets a limit for the buoy motion.

In the following section, the experimental setup at the Lysekil research site will be described. In section III a theoretical expression for the expected performance of L1 will then be derived. Section IV will describe the collection of experimental data. The results will then be introduced and discussed in sections $\mathrm{V}$ to VII.

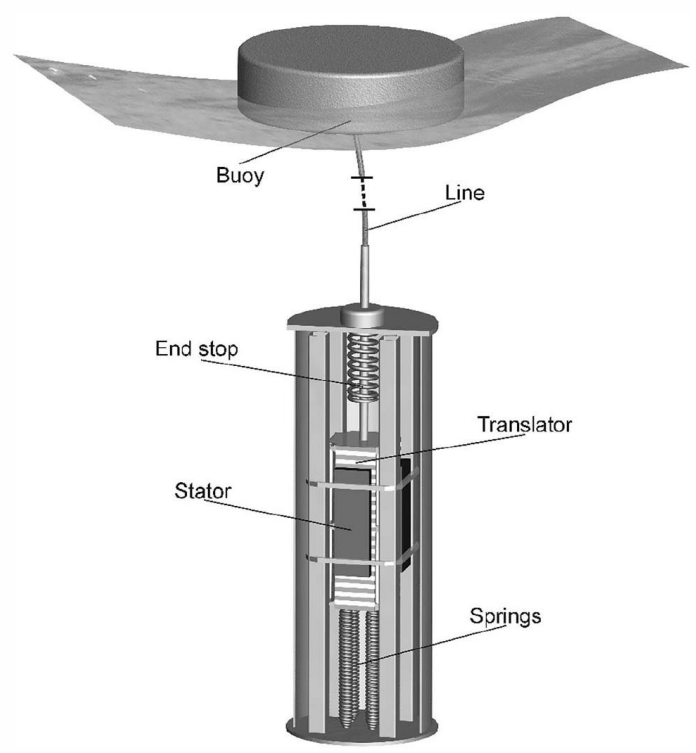

Figure 1. Illustration of the technology studied.

\section{EXPERIMENTAL SETUP}

The Lysekil research site is located some miles southwest of the town of Lysekil, on the Swedish west coast. Within the site, $\mathrm{L} 1$ is positioned at $58^{\circ} 11.7^{\prime} \mathrm{N}, 11^{\circ} 22.4^{\prime} \mathrm{E}$, at 25 meters depth. Surrounding L1 are a number of "biology buoys" which serve as a base for studies on environmental impact [10]. A sea cable is drawn from L1 to a measuring station onshore. Some 50 meters west of L1, a wave measuring buoy has been in operation since 2004.

The absorbed power (defined in section IV-A) from L1 is measured in the station on shore, where the converted electric power is dissipated in a $\Delta$-connected resistive load. The load resistance is adjustable, and the test results have been achieved with loads of $2.2 \Omega, 4.9 \Omega$ and $10 \Omega$ respectively. Data describing L1 can be found in table I, where "Max. stroke of translator" describes the conditions for which the translator will not hit the end stop (see Fig. 1). The linear generator is a three-phase synchronous permanent magnet generator [7].

\section{THEORY}

When the buoy moves in the waves, so does the translator inside the generator. When the waves reach a certain size, the 


\begin{tabular}{lcc}
\hline Buoy diameter & $d$ & $3 \mathrm{~m}$ \\
Buoy height & $h$ & $0.8 \mathrm{~m}$ \\
Buoy mass & $m$ & $1000 \mathrm{~kg}$ \\
Nominal draft of buoy & $D$ & $0.4 \mathrm{~m}$ \\
Translator length & $l_{T}$ & $1.868 \mathrm{~m}$ \\
Stator length & $l_{S}$ & $1.264 \mathrm{~m}$ \\
Max. stroke of translator & $s$ & $\pm 0.90 \mathrm{~m}$ \\
Nominal power & $P_{n}$ & $10 \mathrm{~kW}$ \\
Nominal speed & $v_{n}$ & $0.67 \mathrm{~m} / \mathrm{s}$ \\
\hline
\end{tabular}

Table I

FEATURES OF L1

translator will partly leave the stator, either on one side or on both. The active length, i.e. the length for which the translator and stator overlap, will thus be reduced and the performance of the generator will change. The position of the translator is denoted $x$, where $x=0$ means that the translator is centered in the stator. The translator will leave the stator if

$$
|x|>\frac{l_{T}-l_{S}}{2} \equiv \frac{\Delta}{2},
$$

where $l_{T}$ and $l_{S}$ are the translator and stator lengths, as in table I, and where the difference in length between translator and stator is denoted $\Delta$. For a sinusoidal motion of the translator, the changes in active length of the generator will depend on the amplitude of the motion and the offset of the equilibrium from $x=0$. For an amplitude of $H / 2$ and an offset $u$, we can set the following conditions for the motion:

Case 1: $\quad|u|+\frac{H}{2} \leq \frac{\Delta}{2}$ Translator remains inside the stator.

Case 2: $\begin{aligned} \frac{\Delta}{2} & <|u|+\frac{H}{2} \\ -\frac{\Delta}{2} & \leq|u|-\frac{H}{2} \leq \frac{\Delta}{2}\end{aligned}$ Translator leaves stator on one side but comes back in completely.

Case 3: $\quad \frac{\Delta}{2}<|u|-\frac{H}{2}$ Translator leaves stator on one side and does not come back in completely.

Case 4: $\quad|u|-\frac{H}{2}<-\frac{\Delta}{2} \quad$ Translator leaves stator on both sides

In Fig. 2 a sinusoidal translator motion $x=\frac{H}{2} \sin \omega t+u$ and the resulting active length $y(t)$ of the generator are plotted for Case 4, i.e. when the translator leaves the stator on both sides. The translator partially leaves the stator at $t_{1}$ and $t_{3}$, and fully comes back inside at $t_{2}$ and $t_{4}$. For this situation the function $y(t)$ over one period $T$ can be described as

$$
y(t)=\left\{\begin{array}{cc}
l_{S} & 0<t \leq t_{1} \\
-\frac{H}{2} \sin \omega t+l_{s}+\frac{\Delta}{2}-u & t_{1}<t \leq t_{2} \\
l_{S} & t_{2}<t \leq t_{3} \\
\frac{H}{2} \sin \omega t+l_{s}+\frac{\Delta}{2}+u & t_{3}<t \leq t_{4} \\
l_{S} & t_{4}<t \leq T
\end{array}\right.
$$

where

$$
\left\{\begin{array}{l}
t_{1}=\frac{1}{\omega} \arcsin \left(\frac{\Delta-2 u}{H}\right) \\
t_{2}=\frac{T}{2}-\frac{1}{\omega} \arcsin \left(\frac{\Delta-2 u}{H}\right) \\
t_{3}=\frac{T}{2}+\frac{1}{\omega} \arcsin \left(\frac{\Delta+2 u}{H}\right) \\
t_{4}=T-\frac{1}{\omega} \arcsin \left(\frac{\Delta+2 u}{H}\right)
\end{array} .\right.
$$
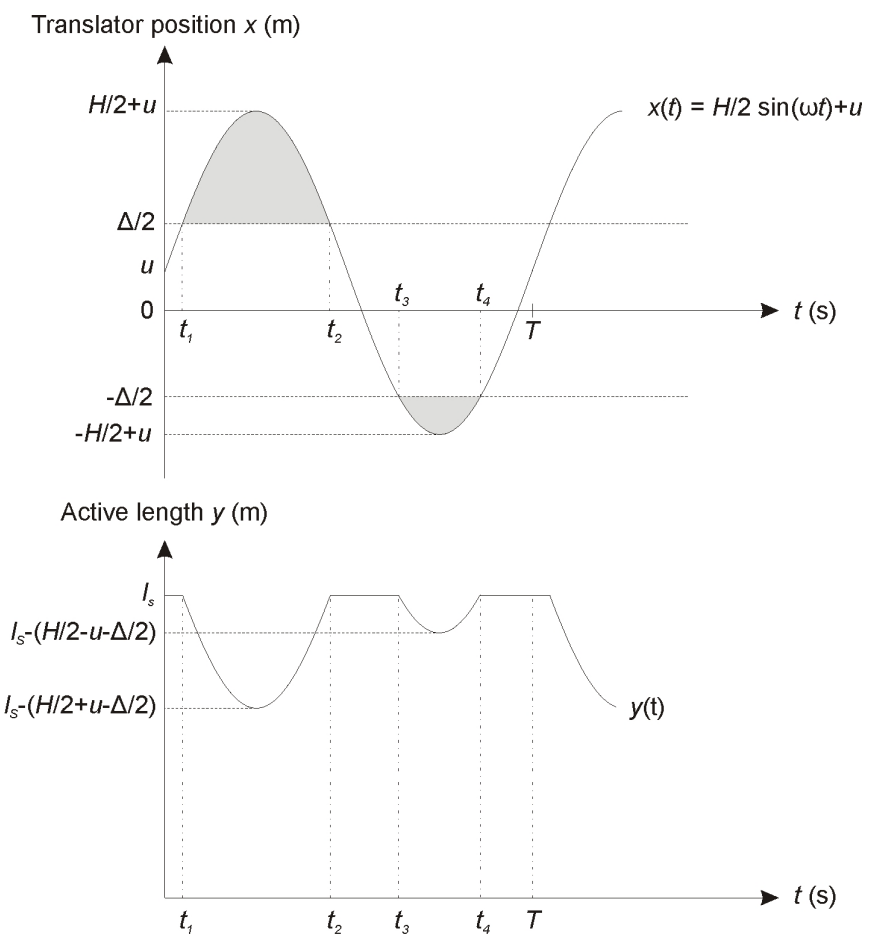

Figure 2. Translator position $x(t)$ and generator active length $y(t)$ for Case 4.

For Case 1 and 2 the function $y$ becomes simpler. For Case 1 $y(t)=l_{S}$ for all times, and for Case $2 y(t)=l_{S}$ for $t_{2}<t \leq$ $T$. For Case 3 the active length will vary as a sine at all times: $y(t)=\frac{H}{2} \sin \omega t+l_{S}-\left(|u|-\frac{\Delta}{2}\right)$. The equations above are valid as long as the translator does not move completely out of the stator, i.e. as long as $\frac{H}{2}+|u| \leq \frac{l_{T}+l_{S}}{2}$. This is always the case for L1.

We would expect that the generator performance decreases when the active length decreases. From a generator geometry perspective, over one period it can be assumed that the integral of the function $y(t)$ over the full active length $l_{S}$ describes the expected deviation from optimal performance through the factor $Q$ :

$$
Q=Q(H, u)=\frac{1}{T} \int_{0}^{T} \frac{y(t)}{l_{S}} d t
$$

Inserting the expressions for $y(t)$ into Eq. 4 and evaluating the integral gives

Case 1: $Q=1$

Case 2: $\quad Q=1+\frac{H}{2 \pi l_{S}}\left(\frac{\alpha \pi}{2}-\alpha \arcsin \alpha-\cos (\arcsin \alpha)\right)$

Case 3: $\quad Q=1+\frac{H \alpha}{2 l_{S}}=1+\frac{\Delta-2|u|}{2 l_{S}}$

Case 4: $\quad Q=1+\frac{H}{2 \pi l_{S}}\left(\frac{\alpha \pi}{2}-\alpha \arcsin \alpha-\cos (\arcsin \alpha)+\right.$

$$
\left.+\frac{\beta \pi}{2}-\beta \arcsin \beta-\cos (\arcsin \beta)\right)
$$

where we have introduced $\alpha \equiv(\Delta-2|u|) / H$ and $\beta \equiv(\Delta+$ $2|u|) / H$. The surface $Q(H, u)$ has been plotted for $0 \mathrm{~m}<$ $H<3 \mathrm{~m}$ and $-0.8 \mathrm{~m} \geq u \geq 0.8 \mathrm{~m}$ in Fig. 3. Although there are details that are difficult to display in two dimensions, it can be seen that $Q$ decreases as $|u|$ increases, for the part where $Q<1$. $Q$ also decreases with increasing $H$ if $|u|$ is not too 
large, i.e. as long as we are not in the region covered by case 3 , for which $Q$ depends only on $u$.

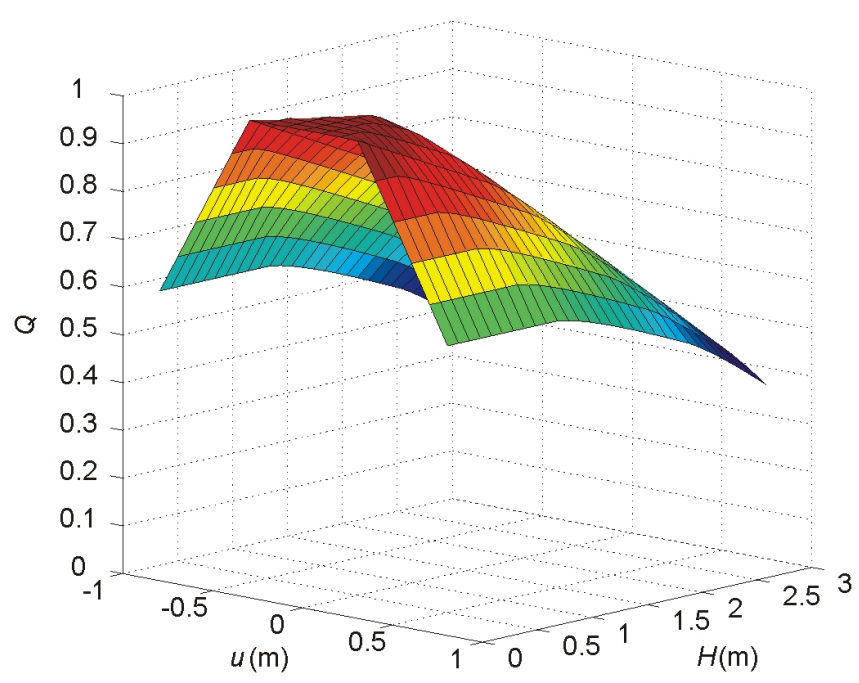

Figure 3. The factor $Q$ as a function of $H$ and $u$. Color has been added to enhance the readability of the figure.

In reality, neither ocean waves nor the translator motions are sinusoidal. However, using the significant wave height $H_{m 0}$ as a characteristic wave height and using the still water level $w$ as a characteristic equilibrium offset, we expect that the measured relative power absorption of $\mathrm{L} 1$ as a function of $H_{m 0}$ and $w$ should exhibit similar characteristics as $Q\left(H_{m 0}, w\right)$.

\section{DATA GATHERING}

\section{A. Measurements on LI}

Measurements of absorbed power were made from March to May of 2006, with a sampling frequency of $50 \mathrm{~Hz}$. By absorbed power is meant power consumed in the windings of the generator, the sea cable and the load on shore. Mechanical losses and iron losses in the generator are not accounted for. "Absorbed power" is thus somewhat less than what is actually removed from the waves. The absorption in the generator and sea cable are calculated via measurements of currents and knowledge of generator and cable resistances. The data on absorbed power used in this paper are half hour averages.

\section{B. Wave Data}

Data on the power of incoming waves are taken from the wave measurement buoy. The buoy measures vertical position with a sampling frequency of $2.56 \mathrm{~Hz}$. For each half hour, the wave spectrum is calculated, as well as the spectral moments $m_{0}$ and $m_{-1}$. The energy period $T_{m 0-1}$ and significant wave height $H_{m 0}$ are are then found through

$$
T_{m 0-1} \equiv \frac{m_{-1}}{m_{0}}, H_{m 0} \equiv 4 \sqrt{m_{0}} \text {. }
$$

For the time period in question, $T_{m 0-1}$ is in the range [2.2 $\mathrm{s}$, $13.5 \mathrm{~s}]$ and $H_{m 0}$ in the range $[0 \mathrm{~m}, 2.7 \mathrm{~m}]$. Finally, the incoming power per meter wave front $P_{W}$ is calculated, using the values of $T_{m 0-1}$ and $H_{m 0}$ (for a more detailed description of these methods, see e.g. [11] or [12]):

$$
P_{W}=\frac{\rho g^{2}}{64 \pi} T_{m 0-1} H_{m 0}^{2} .
$$

$P_{W}$ is in the range $[0 \mathrm{~kW} / \mathrm{m}, 22.5 \mathrm{~kW} / \mathrm{m}]$.

\section{Water Levels}

SMHI (the Swedish Institute for Meteorology and Hydrology) continuously measures water levels on the Swedish west coast. Data for the months in question was acquired from the station 'Smögen", located at $58^{\circ} 21^{\prime}$ N, $11^{\circ} 13$ ' E. Water levels $w$ are measured each hour and given in meters above or below the average water level, $w=0$. To match the wave climate data and absorption data, a water level measured at a certain time is assumed to be valid the half hour before and after that time. The water levels from Smögen are in the range $[-0.70 \mathrm{~m},+0.46 \mathrm{~m}]$. The distribution of water levels during the time of measurements can be seen in Fig. 4(a), and the relation between significant wave height and water levels can be seen in Fig. 4(b).

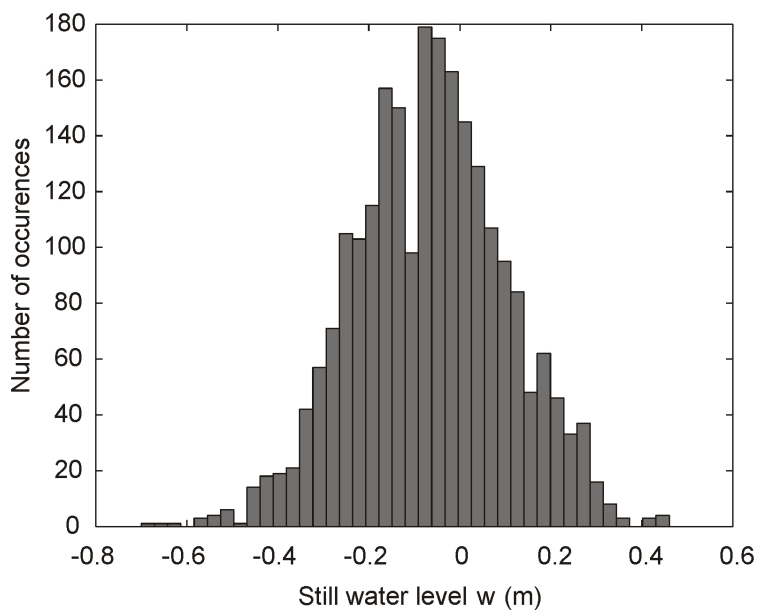

(a) Distribution of measured still water levels

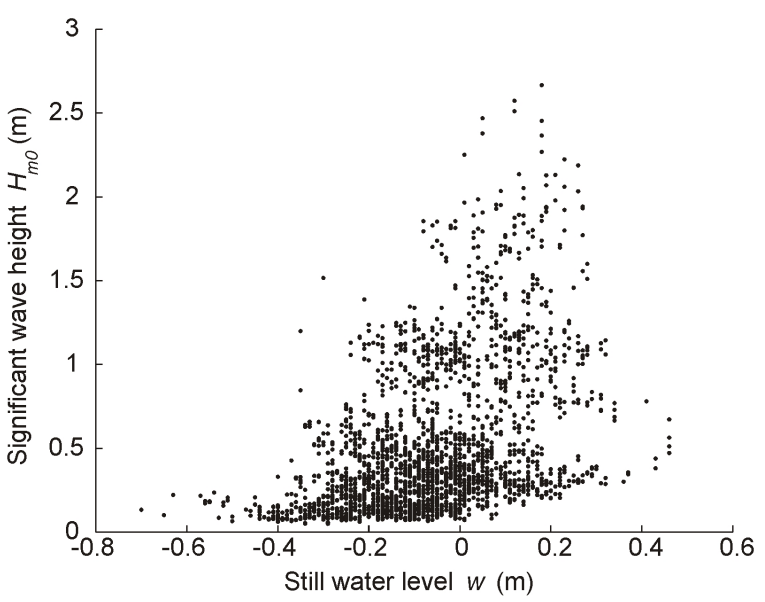

(b) Significant wave height vs. measured still water levels

Figure 4. Statistics on the distribution of still water levels and significant wave heights. 


\section{RESULTS}

From the data on absorbed power (section IV-A) and incoming power (section IV-B), the relative absorption factor $\sigma$ has been calculated for each half hour in the time range:

$$
\sigma=\frac{\text { absorbed power }}{\text { incoming power }}=\frac{\text { absorbed power }}{3 P_{W}} .
$$

Incoming power is here defined as the power coming in across the physical width of the buoy, which is three meters. The data set consists of 2324 absorption values. In Fig. 5 (a) and (b) these have been plotted against corresponding still water level values $w$ and significant wave heights $H_{m 0}$ for the three different electrical loads. It can be seen that $\sigma_{\max }=0.25$. This value will be used to plot the theoretically expected performance below.

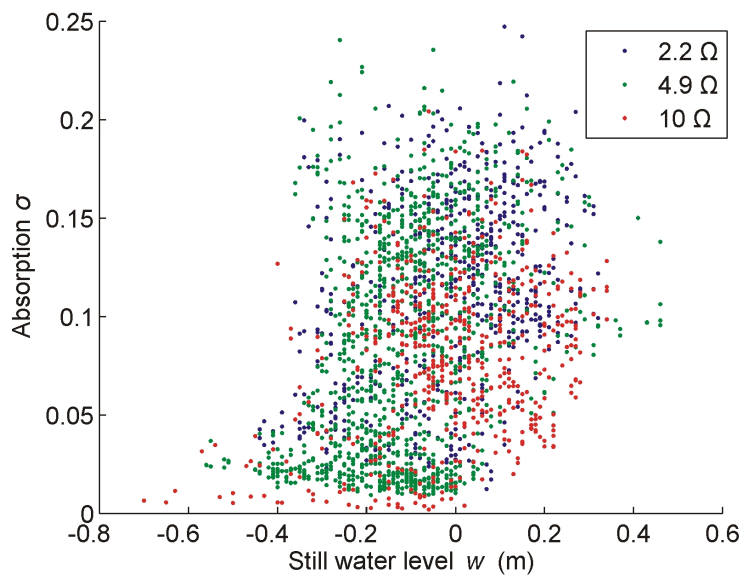

(a) Relative absorption $\sigma$ vs. water level $w$

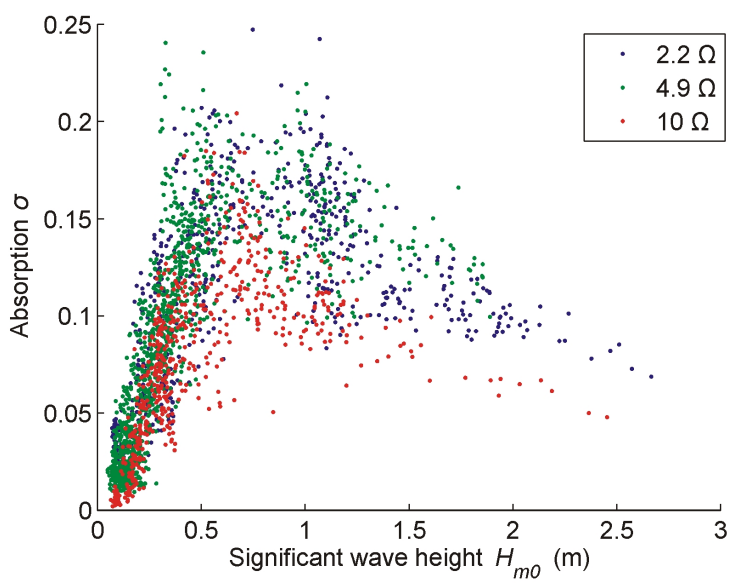

(b) Relative absorption $\sigma$ vs. significant wave height $H_{m 0}$

Figure 5. Absorption values for different still water levels and significant wave heights.

In the next step, we would like to compare the experimental values with the theoretical factor $Q$ that was derived in section III. Since $Q$ describes the expected deviation from optimal performance, $\sigma_{\max } \cdot Q\left(H_{m 0}, w\right)$ will give the expected performance in this case.

Fig. 6 is a three-dimensional plot of measured absorption values versus significant wave height and water levels, together with the surface $\sigma_{\max } \cdot Q\left(H_{m 0}, w\right)$. Again, the difficulty of displaying three-dimensional data in two dimensions puts a limit on what can be displayed. Therefore in Figs. 7(a)-(d) and 8(a)-(c), different sets of the data is displayed to enhance the readability. In the $H_{m 0}$-direction, the data has been divided into four sections and in the $w$-direction into three sections.

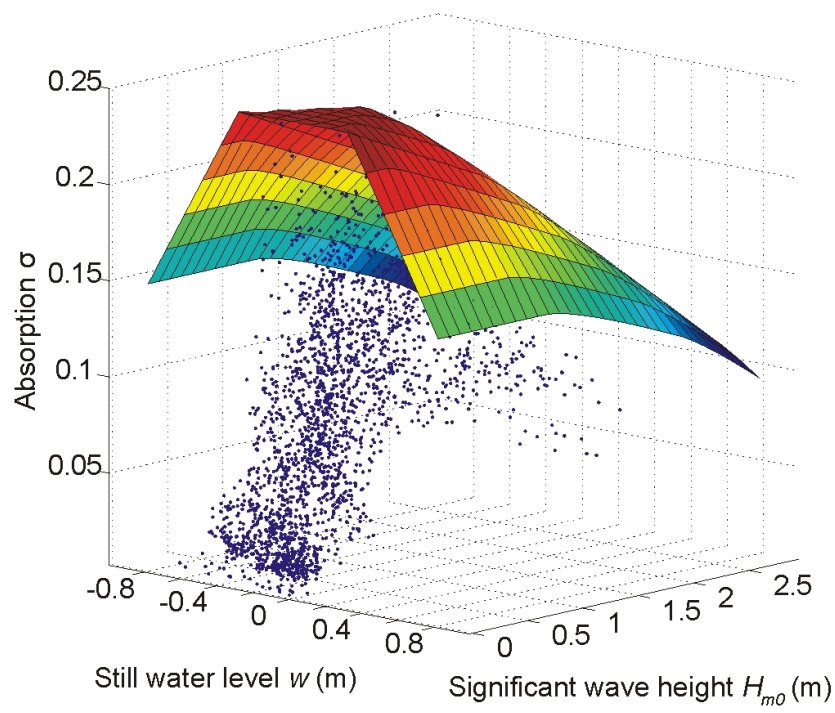

Figure 6. Experimental absorption values (dots) and theoretical absorption factor (surface). Color has been added to the surface to increase readability.

When looking at Figs. 6-8 it must be kept in mind that plotting the surface $\sigma_{\max } \cdot Q\left(H_{m 0}, w\right)$ as the theoretically expected limit is not the only possible choice. To compare the factor $Q$ to the experimental values some scaling is necessary, but it would be possible to use other factors than $\sigma_{\max }$. All choices are arbitrary to some extent, but it was the feeling here that $\sigma_{\max }$ was the most straightforward choice.

\section{DISCUSSION}

The experimental absorption values in Figs. 7 and 8 are quite scattered for each value of $H_{m 0}$ and $w$. However, all values but two stay below the surface $\sigma_{\max } \cdot Q\left(H_{m 0}, w\right)$. The two points can also be seen if Fig. 6. This is an indication that that the surface $\sigma_{\max } \cdot Q\left(H_{m 0}, w\right)$ could represent an upper bound to the performance of L1.

Turning to Fig. 7, a general decrease in absorption for increasing $|w|$ can be seen, although not as clearly in all four cases. For the lowest significant wave heights, displayed in Fig. 7(a), most of the measured values lie significantly lower than predicted by the theory. For such small waves other factors than total active generator area become dominant, and the performance of the generator tends to zero as the significant wave height decreases. This is expected, since less and less of the maximum generator stroke is utilized. The measurements of wave heights and periods from the wave measurement buoy are also less accurate for small waves. This means that the error in describing the incoming energy becomes larger, which further means that the values of relative absorbed energy become less accurate. The discrepancy between theory and 


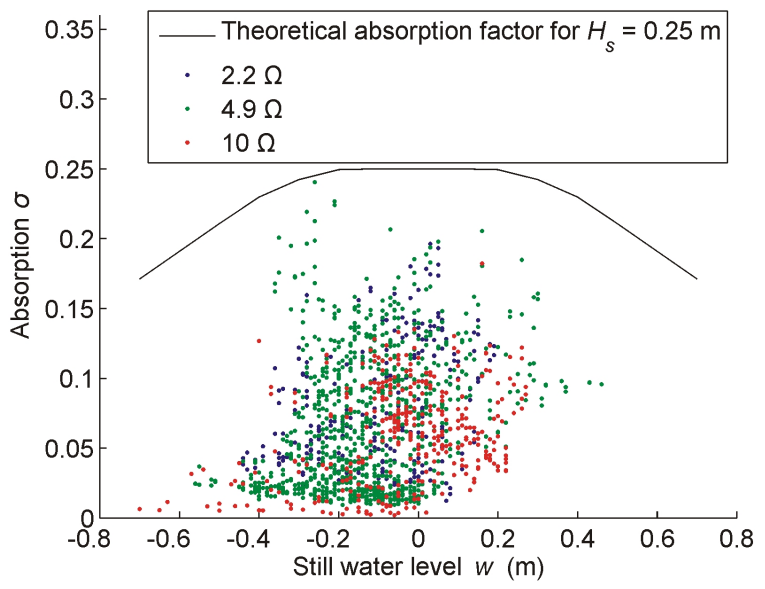

(a) Absorption values for $0 \mathrm{~m} \leq H_{m 0}<0.5 \mathrm{~m}$

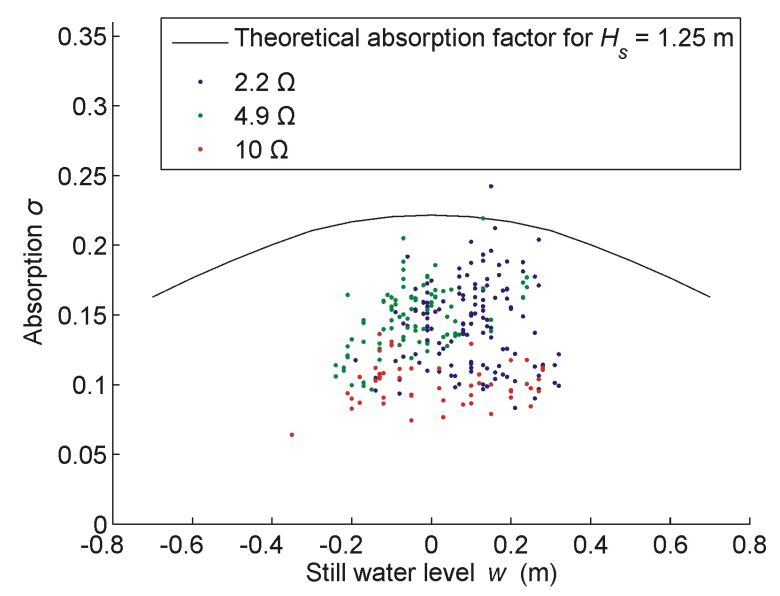

(c) Absorption values for $1.0 \mathrm{~m} \leq H_{m 0}<1.5 \mathrm{~m}$

Figure 7. Absorption values for four sets of significant wave heights

experiment for low significant wave heights can also be seen in Fig. 8.

In Figs. 7(b)-(d), the fit between experiment and theory is better than in Fig. 7(a). However, as the significant wave height increases, the measured values tend to be grouped closer to $w=0$ which makes it hard to draw conclusions on the validity of the theory for large $|w|$. Arguably, Fig. 7(b) displays the best fit between theory and experiment. The measured values are scattered but are bound by the theoretical values on the upper side.

Looking instead at how absorption and significant wave height are related, the correlation is somewhat clearer. In Figs. 8(b) and (c) it can be seen that the absorption values decrease as $H_{m 0}$ increases, as long as $H_{m 0}>0.5 \mathrm{~m}$. The rate at which the decrease takes place is similar to the one predicted by the theory, although at a lower level. This level is also dependent on the chosen load (this issue is studied in more detail in [9]). For absorption values where $w \leq-0.15 \mathrm{~m}$ (Fig. 8(a)), there is not enough data with high significant wave height to draw any clear conclusion. For small waves $\left(H_{s}<0.5\right)$ the theoretical values do not match the experimental data at all, as was noted above.

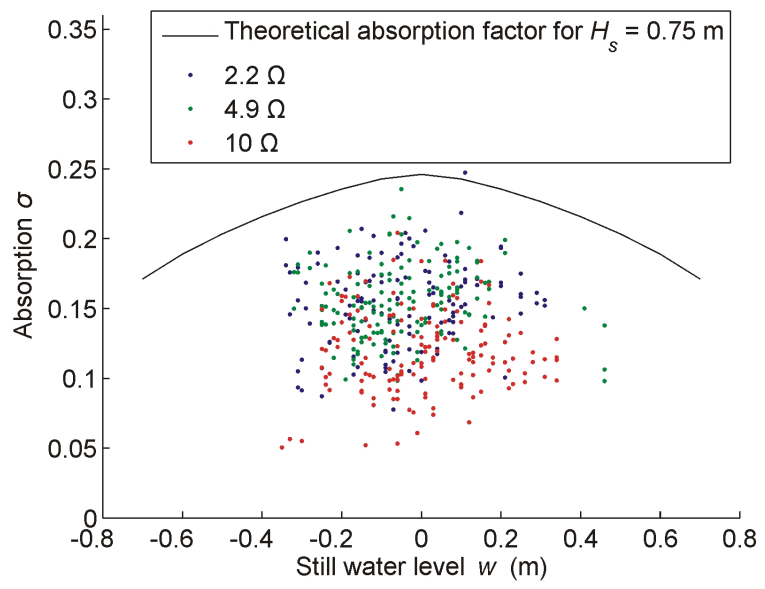

(b) Absorption values for $0.5 \mathrm{~m} \leq H_{m 0}<1.0 \mathrm{~m}$

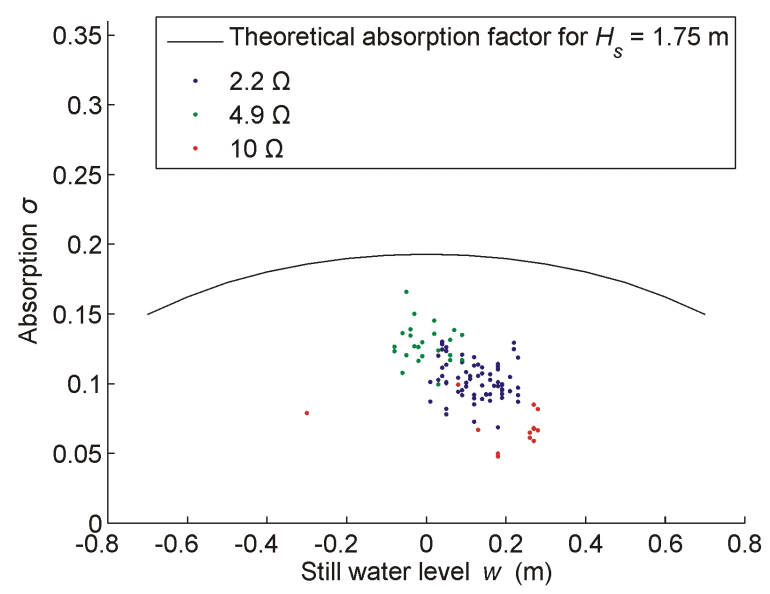

(d) Absorption values for $H_{m 0} \geq 1.5 \mathrm{~m}$

It can be seen that for $w>0 \mathrm{~m}$, there are fewer and fewer low values of absorption when $w$ grows (Fig. 5(a)). Conversely, for $w<-0.40 \mathrm{~m}$ there are no values of absorption above 0.05 , and the remaining values tend to zero as $w$ decreases. This can be explained when looking at Fig. 4(b), where it can be seen that for low still water levels the waves are always small, and for high water levels, there are fewer and fewer small waves. This corresponds likely to periods of high and low air pressure, where the former will create lower still water levels and calm weather and the latter will produce higher still water levels and more harsh weather.

Both theory and experimental data suggest that the sensitivity of the system to changes in still water levels is fairly low as long as we are in the region of approximately $\pm 0.20 \mathrm{~m}$ from the mean level. Such sea states represent $72.3 \%$ of the data set, implying that a decrease of performance due to changing still water levels is a quite small problem at the Lysekil research site.

The experimental data from L1 will always exhibit large spreads, regardless of what parameters are studied, due to the many factors that cannot be controlled. One example of such a factor is that there are many possible actual series of sea 


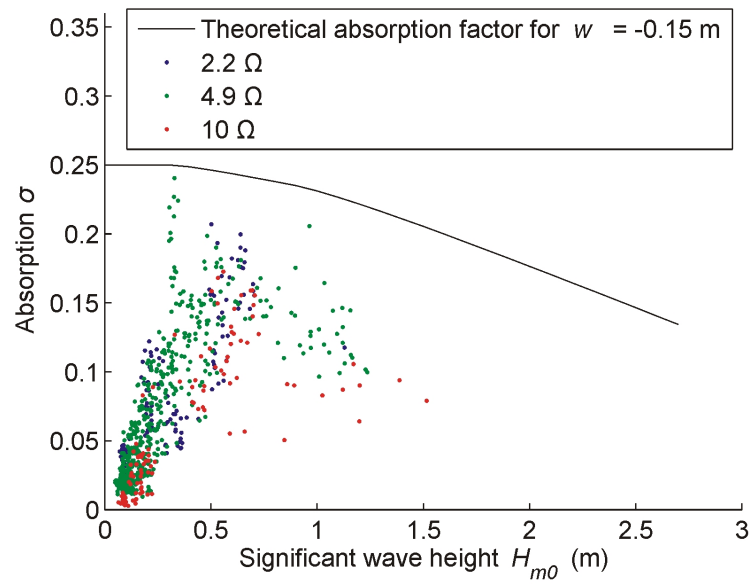

(a) Absorption values for $w \leq-0.15 \mathrm{~m}$

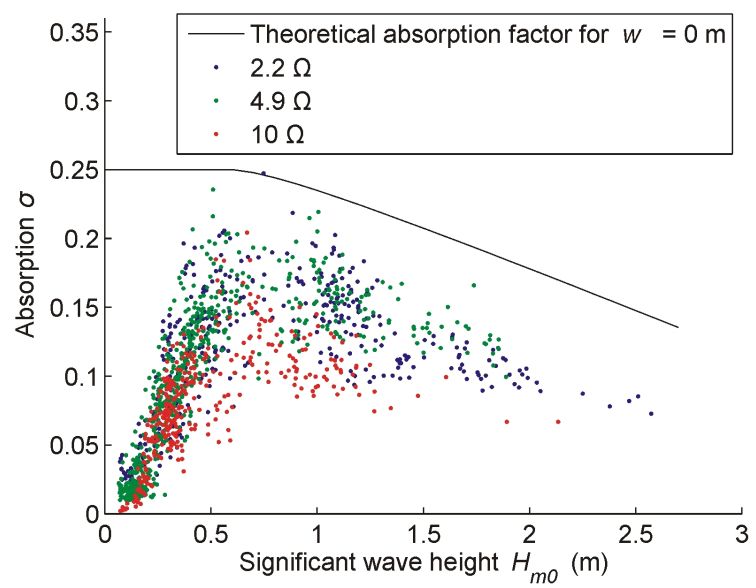

(b) Absorption values for $-0.15 \mathrm{~m}<w<0.15 \mathrm{~m}$

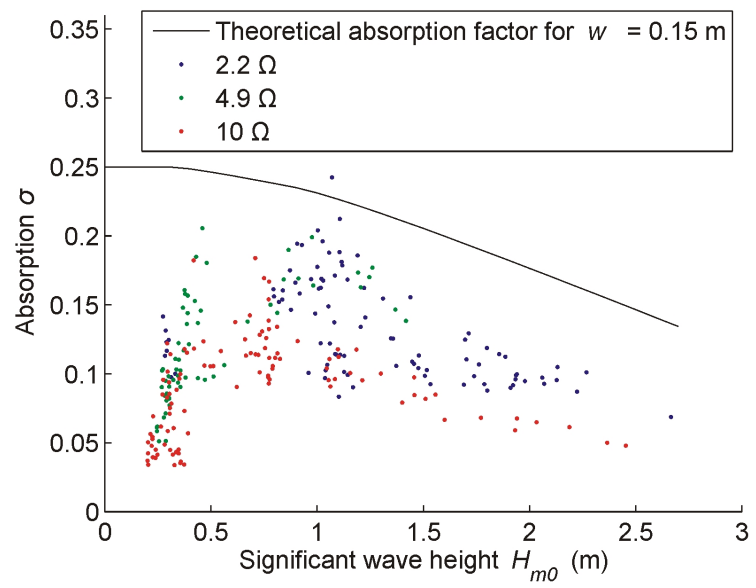

(c) Absorption values for $w \geq 0.15 \mathrm{~m}$

Figure 8. Absorption values for three sets of still water levels

surface elevations that could produce the same significant wave height. Thus, there are different energy periods associated with one significant wave height. To study the influence of varying energy periods, three-dimensional plots were made both for wave height/energy period/absorption and still water level/energy period/absorption. However, no patterns could be found, and these plots have not been included.

\section{CONCLUSIONS}

A theoretical expression was derived to describe the expected change in relative power absorption for changing still water levels $w$ and significant wave heights $H_{m 0}$ for a wave energy converter with a linear generator. The theory predicted decreasing power absorption as $H_{m 0}+|w|$ increases. The measured experimental values for relative absorption of the wave energy converter $L 1$ were analyzed. The experimental values exhibit similar characteristics as the theoretical expression, although at a lower level for the most part. The similarities were clearer in the $H_{m 0}$-direction than in the $w$-direction, possibly due to a lack of experimental data for small and large $w$.

\section{ACKNOWLEDGMENTS}

This project is carried out within the frames of the Swedish Centre for Renewable Electric Energy Conversion at Uppsala university. It is supported by The Swedish Energy Agency, VINNOVA, Statkraft AS, Draka Cable AB, Vattenfall AB, Fortum OY, The Gothenburg Energy Research Foundation, The Göran Gustavsson Research Foundation, Vargöns Research Foundation, Falkenberg Energy AB, the Swedish Research Council grant no. 621-2009-3417 and the Wallenius Foundation. Thanks are given to The Swedish Institute for Meteorology and Hydrology for providing water level data. Magnus Rahm is acknowledged for his construction work with L1 and Olle Svensson and Cecilia Boström for their work with measurements and load systems. Mikael Eriksson initiated the thoughts on water level impacts.

\section{REFERENCES}

[1] E. B. Agamloh, A. K. Wallace, and A. von Jouanne, "A novel directdrive ocean wave energy extraction concept with contact-less force transmission system," Renewable Energy, vol. 33, pp. 520-529, 2008.

[2] C. B. Boake, T. J. T. Whittaker, M. Folley, and H. Ellen, "Overview and initial operational experience of the LIMPET wave energy plant," in Proceedings of The Twelfth (2002) International Offshore and Polar Engineering Conference, 2002, pp. 586-594.

[3] M. C. Carcas, "The OPD [ocean power delivery] pelamis WEC [wave energy converter]: Current status and onward programme (2002)," International Journal of Ambient Energy, vol. 24, 2003.

[4] J. P. Kofoed, P. Frigaard, E. Friis-Madsen, and H. C. Sørensen, "Prototype testing of the wave energy converter Wave Dragon," Renewable Energy, vol. 31, pp. 181-189, 2006.

[5] M. Leijon, O. Danielsson, M. Eriksson, K. Thorburn, H. Bernhoff, J. Isberg, J. Sundberg, I. Ivanova, E. Sjöstedt, and O. Ågren, "An electrical approach to wave energy conversion," Renewable Energy, vol. 31, no. 9, pp. 1309-1319, July 2006.

[6] H. Polinder, M. E. C. Damen, and F. Gardner, "Linear PM generator system for wave energy conversion in the AWS," IEEE Transactions on Energy Conversion, vol. 19, pp. 583-589, 2004.

[7] O. Danielsson, M. Eriksson, and M. Leijon, "Study of a longitudinal flux permanent magnet linear generator for wave energy converters," International Journal of Energy Research, vol. 30, no. 14, pp. 11301145, 2006.

[8] M. Eriksson, R. Waters, O. Svensson, J. Isberg, and M. Leijon, "Wave power absorption: Experiments in open sea and simulation," Journal of Applied Physics, vol. 102, p. 084910 (5 pages), 2007.

[9] R. Waters, M. Stålberg, O. Danielsson, O. Svensson, S. Gustafsson, E. Strömstedt, M. Eriksson, J. Sundberg, and M. Leijon, "Experimental results from sea trials of an offshore wave energy system," Applied Physics Letters, vol. 90, p. 034105 (3 pages), 2007. 
[10] O. Langhamer and D. Wilhelmsson, "Wave power devices as artificial reefs," in Proceedings of the 7th European Wave and Tidal Energy Conference, Porto, Portugal, 2007.

[11] J. Cruz, Ed., Ocean Wave Energy - Current Status and Future Perspectives. Springer-Verlag, 2008.

[12] J. Falnes, "A review of wave-energy extraction," Marine Structures, vol. 20, pp. 185-201, 2007. 